\title{
Unscheduled return visits to a Dutch inner-city emergency department
}

\author{
M Christien van der Linden ${ }^{1 *}$, Robert Lindeboom ${ }^{2}$, Rob de Haan ${ }^{3}$, Naomi van der Linden ${ }^{4}$, Ernie RJT de Deckere ${ }^{1}$, \\ Cees Lucas ${ }^{2}$, Steven J Rhemrev ${ }^{1}$ and J Carel Goslings ${ }^{5}$
}

\begin{abstract}
Background: Unscheduled return visits to the emergency department (ED) may reflect shortcomings in care. This study characterized ED return visits with respect to incidence, risk factors, reasons and post-ED disposition. We hypothesized that risk factors for unscheduled return and reasons for returning would differ from previous studies, due to differences in health care systems.

Methods: All unscheduled return visits occurring within 1 week and related to the initial ED visit were selected. Multivariable logistic regression was conducted to determine independent factors associated with unscheduled return, using patient information available at the initial visit. Reasons for returning unscheduled were categorized into illness-, patient- or physician-related. Post-ED disposition was compared between patients with unscheduled return visits and the patients who did not return.

Results: Five percent $(n=2,492)$ of total ED visits $(n=49,341)$ were unscheduled return visits. Patients with an urgent triage level, patients presenting during the night shift, with a wound or local infection, abdominal pain or urinary problems were more likely to return unscheduled. Reasons to revisit unscheduled were mostly illness-related (49\%) or patient-related (41\%). Admission rates for returning patients (16\%) were the same as for the patients who did not return (17\%).

Conclusions: Apart from abdominal complaints, risk factors for unscheduled return differ from previous studies. Short-term follow-up at the outpatient clinic or general practitioner for patients with urgent triage levels and suffering from wounds or local infections, abdominal pain or urinary problem might prevent unscheduled return.
\end{abstract}

Keywords: Emergency service; Hospital; Emergency department; Unscheduled return visits

\section{Background}

Unscheduled return visits to the emergency department (ED) are visits of patients who were seen in the ED and then return for an unscheduled visit for the same complaint. Unscheduled return visits may reflect a failure of the patients' treatment or discharge plan [1]. Different numbers of unscheduled return visits have been reported, ranging from $2 \%$ to $5 \%$ of the patients returning to the ED within 2 to 8 days after their initial visit [2-9]. The reasons for unscheduled return are frequently grouped into illness-related factors (such as disease progression), patient-related factors (such as patients who left against medical advice during

\footnotetext{
* Correspondence: c.van.der.linden@mchaaglanden.nl

${ }^{1}$ Accident and Emergency Department, Medical Centre Haaglanden, P.O. Box 432, The Hague 2501 CK, The Netherlands

Full list of author information is available at the end of the article
}

their initial visit) and physician-related factors (such as medical errors) [3,6,7]. Unscheduled return visits are more common in patients who lack access to primary care [10] and in patients with no health insurance [11]. Unscheduled return is associated with frequent ED use [12] and a greater risk of adverse events and mortality [13].

In order to reduce unscheduled return visits, researchers have focused on risk factors that could help identify patients at risk for unscheduled return [11,14-19]. Most of these studies have been performed in Canada and the USA and reported acute triage category [14,16], arrival in the evening [14] and a respiratory diagnosis [19] as risk factors for paediatric unscheduled return. A digestive diagnosis was reported as risk factor for unscheduled return in patients 65 years of age or older [17,18]. Having no insurance, a low triage category and suffering from dermatologic

\section{空}


conditions [11] were risk factors for unscheduled return in a mixed (adults and children) population.

In the Netherlands, the incidence of unscheduled ED return is unknown. We expect however that the incidence is lower than described in previous studies. Because all Dutch citizens have a general practitioner (GP) and GP services are available 24/7, patients should present at their GP instead of at the ED when they have ongoing complaints. We also hypothesize that the type of risk factors associated with unscheduled return differs from other studies, given the difference in health care systems. Health insurance is compulsory for all Dutch citizens, and health insurers are obliged to accept anyone who applies for standard health insurance.

The objectives of this study were to determine the incidence of unscheduled ED return visits, to identify the risk factors for these return visits, to assess the reasons for unscheduled return and to describe the post-ED disposition of patients at their return visit.

\section{Methods}

The study was conducted between 1 October 2009 and 30 September 2010 at the ED of Medical Centre Haaglanden, the Hague, the Netherlands, an urban, 380-bed trauma centre. The annual volume in the ED is approximately 52,000 visits, with a $17 \%$ admission rate.

The following are the methods of measurement used for each objective of the study:

1. To determine the incidence of ED return visits, we performed a database search of the patients' records. Emergency department return visits were included if they took place within 1 week of the initial visit and concerned the same complaint or its direct consequences. Scheduled return visits (visits of patients who were told to come back to the ED) were excluded.

2. To identify factors associated with unscheduled return, we manually reviewed all individual patient charts and compared patients with unscheduled return visits with patients who did not return. We examined factors (available at the initial visit) that were associated with unscheduled return in previous research, including age $[14,20]$, sex $[17,20]$, lacking health insurance [11], lacking a GP [10], triage level $[11,14,16,20]$, arrival time $[14,21]$, length of stay (LOS) [22] and medical complaints $[11,15,18]$. Medical complaints for which a patient visited the ED were retrieved by the triage flow charts recorded by the triage nurse.

3. Reasons for returning unscheduled were categorized into illness-related, patient-related or physicianrelated (Table 1 ), based on examples from previous studies $[6,9,23]$. Categorization was independently done by two researchers (MCL and NL). In case of no agreement, the case was reviewed by a third researcher (ERJTD) and assigned to the category on which two of the three researchers agreed.

4. Post-ED dispositions were the discharge codes after the patients' treatment at the ED, comprising discharge, discharge against medical advice or left without being seen, hospital admission to a regular ward or admission to a special care unit (intensive care, coronary care or stroke unit).

All variables were obtained from the hospital electronic database and the medical records. The analyzed patient dataset contained no individual identifiers, maintaining anonymity of subjects. This study was approved by the institutional review board.

\section{Analysis}

Patient and clinical characteristics were summarized using simple descriptive statistics. The $\chi^{2}$ test and unadjusted odds ratios (ORs) were used to assess the univariate association between age, sex, lacking health insurance, lacking a GP, triage level, arrival time, LOS and medical complaints on the one side and unscheduled return within 1 week on the other side. Additionally, all variables that were univariately associated with unscheduled return at $\leq 0.05$ were entered into a multivariate logistic regression model. We also did the analysis with a $<72$-h unscheduled return. Effect sizes were expressed in adjusted ORs. The calibration and overall discriminative ability of the model was assessed with the Hosmer-Lemeshow test and the area under the receiver operating curve (AUC ROC) analysis, respectively [24]. In all analyses, statistical uncertainty was expressed in a 95\% confidence interval (CI). Statistical analyses were performed in PASW (Predictive Analytics Software, version 18, Chicago, IL, USA).

\section{Results}

\section{Return rate}

During the study year, a total of 49,341 ED visits were recorded, of which 4,653 visits were related to unscheduled return (Figure 1). In total, 2,161 patients returned unscheduled to the ED within a week of their initial registration. Since some of them returned more than once, there were 2,492 associated unscheduled return visits, comprising 5.1\% of the total ED visits $(2,492 / 49,341)$.

During the first $72 \mathrm{~h}$ after the initial visit, $1,279 \mathrm{pa}$ tients made 1,330 return visits out of 49,341 total ED visits for an overall 72 -h return rate of $2.7 \%$.

\section{Factors associated with unscheduled return}

Table 2 shows the univariate and multivariate associations between patient/clinical characteristics available at the initial visit and unscheduled ED return within 1 week. Logistic 
Table 1 Reasons for unscheduled return and definitions

\begin{tabular}{|c|c|}
\hline & Definition \\
\hline \multicolumn{2}{|l|}{ Physician-related return } \\
\hline No painkillers prescribed & $\begin{array}{l}\text { The disease or injury warranted pain medication but no prescription was given. The patient returned } \\
\text { primarily because of continued pain }\end{array}$ \\
\hline Treatment error & The physician made the right diagnosis during the initial visit, but made an error in treatment \\
\hline Misdiagnosis & $\begin{array}{l}\text { Medical record review reveals a diagnosis or problem missed by the physician who saw the patient on } \\
\text { the initial visit }\end{array}$ \\
\hline \multicolumn{2}{|l|}{ Patient-related return } \\
\hline Left against medical advice & The patient was seen by a physician and left the ED against medical advice \\
\hline Non-compliance & There is evidence in the medical records that the patient did not follow instructions \\
\hline $\begin{array}{l}\text { Psychiatric disorder and/or substance } \\
\text { abuse }\end{array}$ & $\begin{array}{l}\text { The patient has a psychiatric disorder and/or uses drugs or alcohol, which causes him/her to repeatedly } \\
\text { visit the ED for the same or similar problems. Mentally, the patient is in a chronic stable state }\end{array}$ \\
\hline Left without being seen & The patient was registered in the ED but left before being seen by a physician \\
\hline Patient was instructed to visit own GP & The patient was instructed to return to the GP for re-evaluation but did not go \\
\hline Worrying about health & $\begin{array}{l}\text { The patient's anxiety caused him/her to return to the ED for the same or similar problem. No ancillary } \\
\text { diagnostics were performed and medical management consisted of reassurance only }\end{array}$ \\
\hline \multicolumn{2}{|l|}{ Illness-related return } \\
\hline Recurrent disease process & $\begin{array}{l}\text { The patient has a disease that tends to have recurrent exacerbations (i.e. asthma, sickle cell disease). The } \\
\text { patient was treated appropriately during the initial ED visit, with resolution of symptoms, but later } \\
\text { returned with a second exacerbation of the disease }\end{array}$ \\
\hline Complication & $\begin{array}{l}\text { The patient was treated appropriately during the initial ED visit but returned to the ED because of a } \\
\text { complication of the disease or unpredictable side effect of treatment (e.g. allergic drug reaction) }\end{array}$ \\
\hline Progression of disease & $\begin{array}{l}\text { The medical records reveal that the patient was treated appropriately at the initial visit and that admission } \\
\text { was not indicated. Appropriate follow-up was arranged, but the patient's disease or problem got worse, } \\
\text { and he/she returned to the ED as instructed }\end{array}$ \\
\hline $\begin{array}{l}\text { Ancillary diagnostics performed, no } \\
\text { change in diagnosis }\end{array}$ & $\begin{array}{l}\text { The patient presented with the same or similar problem, ancillary diagnostics were performed but there } \\
\text { was no change in the initial diagnosis or treatment }\end{array}$ \\
\hline
\end{tabular}

regression showed that the following factors had an independent impact on within-week unscheduled return: 'urgent triage level', 'arrival during the night', 'LOS $>1$ h' and the medical complaints 'wound or local infections', 'abdominal

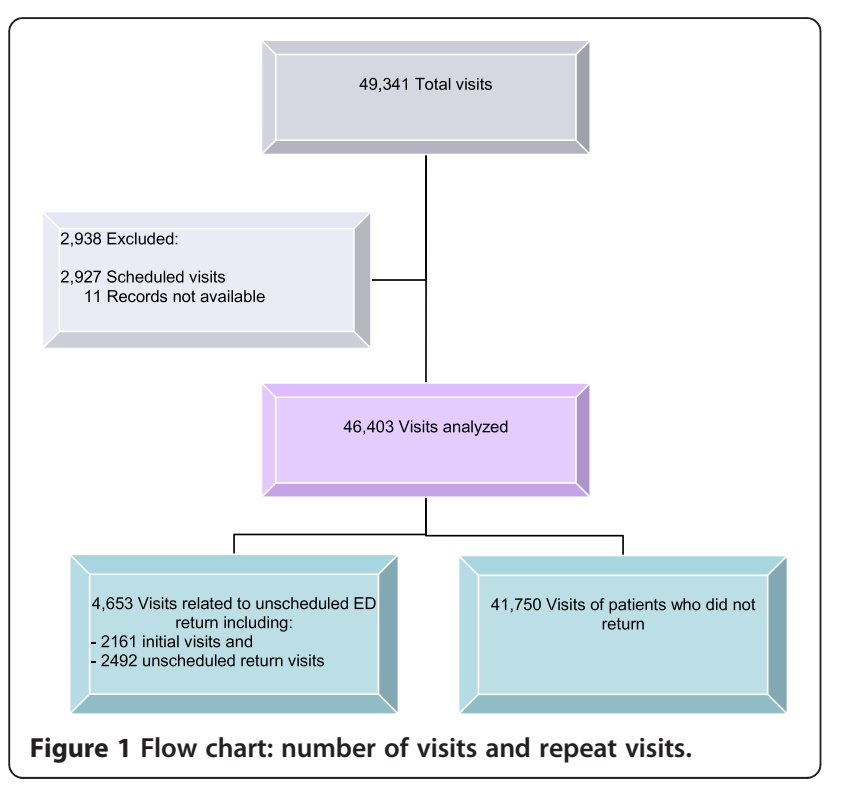

pain' and 'urinary problems' at the initial visit. Patients suffering from 'chest pain', 'feeling unwell' and children triaged with the category 'sick baby' were less likely to return unscheduled. The goodness of fit of the logistic model was moderate $(P=0.75)$, whereas the AUC demonstrated a weak discriminative ability $(0.57 ; 95 \%$ CI 0.56 to 0.59$)$.

Sub-analysis of 72-h return showed that associated factors were the same as for within-week return (data not shown).

\section{Reasons for unscheduled return}

The most common reasons for unscheduled return were illness-related $(n=1,229 ; 49 \%)$, followed by patientrelated $(n=1,018 ; 41 \%)$ and physician-related reasons $(n=245 ; 10 \%)$ (Figure 2$)$.

Within the 1,229 illness-related unscheduled return visits, 'patients in whom ancillary diagnostics was performed while their diagnosis remained unchanged' was the largest subgroup $(n=729 ; 59 \%)$. Within the 1,018 patient-related return visits, patients 'worrying about health' represented the most frequently occurring reason for return (523 visits, 51\%). Within the physician-related return visits, 111 patients (45\%) had 'wrong or delayed diagnoses' during their initial visit, which resulted in 
Table 2 Characteristics associated with unscheduled ED return: univariate and multivariate analysis

\begin{tabular}{|c|c|c|c|c|}
\hline & $\begin{array}{l}\text { Patients who } \\
\text { did not return } \\
(n=41,750)\end{array}$ & $\begin{array}{l}\text { Patients with } \\
\text { unscheduled return visits } \\
(n=2,161)\end{array}$ & $\begin{array}{l}\text { Unadjusted odds } \\
\text { ratio }^{\mathrm{a}, \mathrm{b}}(95 \% \mathrm{Cl}), P \text { value }\end{array}$ & $\begin{array}{l}\text { Adjusted odds } \\
\text { ratio }^{\mathrm{a}, \mathrm{b}, \mathrm{c}}(95 \% \mathrm{Cl}), P \text { value }\end{array}$ \\
\hline Age [mean (standard deviation)] & $38.2(22.3)$ & $39.3(20.7)$ & $1.00(1.00,1.00), 0.03$ & $-{ }^{e}$ \\
\hline Sex, male $[n(\%)]$ & $21,572(51.7)$ & $1,155(53.4)$ & $1.07(0.99,1.17), 0.11$ & - \\
\hline Lacking health insurance $[n(\%)]$ & $1,714(4.1)$ & $97(4.5)$ & $1.01(0.89,1.35), 0.38$ & - \\
\hline Lacking a GP $[n(\%)]$ & $3,255(7.8)$ & $155(7.2)$ & $0.91(0.77,1.08), 0.29$ & - \\
\hline \multicolumn{5}{|l|}{ Triage level $[n(\%)]$} \\
\hline Levels 1 and 2 & $6,482(16.1)$ & $298(14.2)$ & $1.00(0.88,1.15), 0.96$ & $1.13(0.97,1.32), 0.12$ \\
\hline Level 3 & $13,324(33.1)$ & $859(41.0)$ & $1.41(1.28,1.55),<0.01$ & $1.40(1.26,1.55),<0.01$ \\
\hline Levels 4 and 5 (reference category) & $20,428(50.8)$ & $936(44.7)$ & 1 & 1 \\
\hline No triage $^{c}[n(\%)]$ & $1,516(3.6)$ & $68(3.1)$ & $0.86(0.67,1.10), 0.24$ & - \\
\hline \multicolumn{5}{|l|}{ Arrival time $[n(\%)]$} \\
\hline $\begin{array}{l}\text { Day, } 7.30 \text { a.m. to } 3.29 \text { p.m. (reference } \\
\text { category) }\end{array}$ & $17,844(42.7)$ & $882(40.8)$ & 1 & 1 \\
\hline Evening, 3.30 p.m. to 10.59 p.m. & $18,193(43.6)$ & $925(42.8)$ & $1.03(0.94,1.13), 0.56$ & $1.03(0.94,1.14), 0.54$ \\
\hline Night, 11.00 p.m. to 7.29 a.m. & $5,713(13.7)$ & $354(16.4)$ & $1.25(1.10,1.42),<0.01$ & $1.24(1.09,1.41),<0.01$ \\
\hline \multicolumn{5}{|l|}{ Length of stay $[n(\%)]$} \\
\hline$<1$ h (reference category) & $9,918(23.8)$ & $435(20.1)$ & 1 & - \\
\hline 1 to $2 \mathrm{~h}$ & $11,966(28.7)$ & $648(30.0)$ & $1.24(1.09,1.40),<0.01$ & $1.25(1.09,1.42), 0.00$ \\
\hline 2 to $3 \mathrm{~h}$ & $8,804(21.1)$ & $452(20.9)$ & $1.17(1.02,1.34), 0.02$ & $1.16(1.00,1.34), 0.05$ \\
\hline 3 to $4 \mathrm{~h}$ & $5,001(12.0)$ & $283(13.1)$ & $1.29(1.11,1.50),<0.01$ & $1.26(1.06,1.48), 0.01$ \\
\hline$>4 \mathrm{~h}$ & $6,061(14.5)$ & $343(15.9)$ & $1.29(1.12,1.49),<0.01$ & $1.24(1.05,1.45), 0.01$ \\
\hline \multicolumn{5}{|l|}{ Medical complaint [n (\%)] } \\
\hline Extremity-related complaints & $9,789(23.4)$ & $498(23.0)$ & $0.98(0.88,1.08), 0.67$ & - \\
\hline Wounds and local infections & $4,726(11.3)$ & $281(13.0)$ & $1.17(1.03,1.33), 0.02$ & $1.34(1.17,1.54),<0.01$ \\
\hline Other $^{d}$ & $4,480(10.7)$ & $225(10.4)$ & $0.97(0.84,1.11), 0.64$ & - \\
\hline Abdominal pain & 3,597 (8.6) & $269(12.4)$ & $1.51(1.32,1.72),<0.01$ & $1.38(1.20,1.59),<0.01$ \\
\hline Chest pain & $3,547(8.5)$ & $146(6.8)$ & $0.78(0.66,0.93),<0.01$ & $0.78(0.64,0.94), 0.01$ \\
\hline Feeling unwell & $3,124(7.5)$ & $131(6.1)$ & $0.80(0.67,0.96),<0.01$ & $0.75(0.62,0.91), 0.00$ \\
\hline Eye/ear/nose problems and sore throat & $2,317(5.5)$ & $107(5.0)$ & $0.89(0.73,1.08), 0.24$ & - \\
\hline Shortness of breath & $2,085(5.0)$ & $99(4.6)$ & $0.91(0.74,1.12), 0.39$ & - \\
\hline Headache and head injury & $1,943(4.5)$ & $98(4.7)$ & $0.97(0.79,1.20), 0.80$ & - \\
\hline Back pain & $826(2.0)$ & $37(1.7)$ & $0.86(0.62,1.20), 0.39$ & - \\
\hline Trauma, severe & $771(1.8)$ & $32(1.5)$ & $0.80(0.56,1.14), 0.22$ & - \\
\hline Psychiatric problem/substance abuse & $685(1.6)$ & $44(2.0)$ & $1.25(0.92,1.70), 0.16$ & - \\
\hline Rashes & $660(1.6)$ & $32(1.5)$ & $0.94(0.66,1.34), 0.72$ & - \\
\hline Urinary problems & $641(1.5)$ & $59(2.7)$ & $1.80(1.37,2.36),<0.01$ & $1.72(1.31,2.26),<0.01$ \\
\hline Sick baby & $524(1.3)$ & $12(0.6)$ & $0.44(0.25,0.78),<0.01$ & $0.47(0.27,0.84), 0.01$ \\
\hline No medical complaint registered & $2,035(4.9)$ & $91(4.2)$ & $0.86(0.69,1.06), 0.16$ & - \\
\hline
\end{tabular}

${ }^{a}$ Categorical variables (triage level, arrival time and categorized LOS) were entered as 'dummy' variables. ${ }^{b} x^{2}$ test, OR $>1$ indicates an increased risk of unscheduled return. 'Adjusted for included variables (age, triage level, arrival time, LOS, medical complaint) by logistic regression model, based on 42,327 observations (40,234 visits of patients who did not return and 2,093 unscheduled return visits) due to missing values on triage level $(n=1,584)$. ${ }^{d}$ Medical complaints occurring less than 500 times per year (including allergy, dental problems, diabetes, exposure to chemicals, fits, neck pain, pregnancy, sexually acquired infections, testicular pain and vaginal bleeding) were categorized as 'Other'. 'Not in multivariable model. 


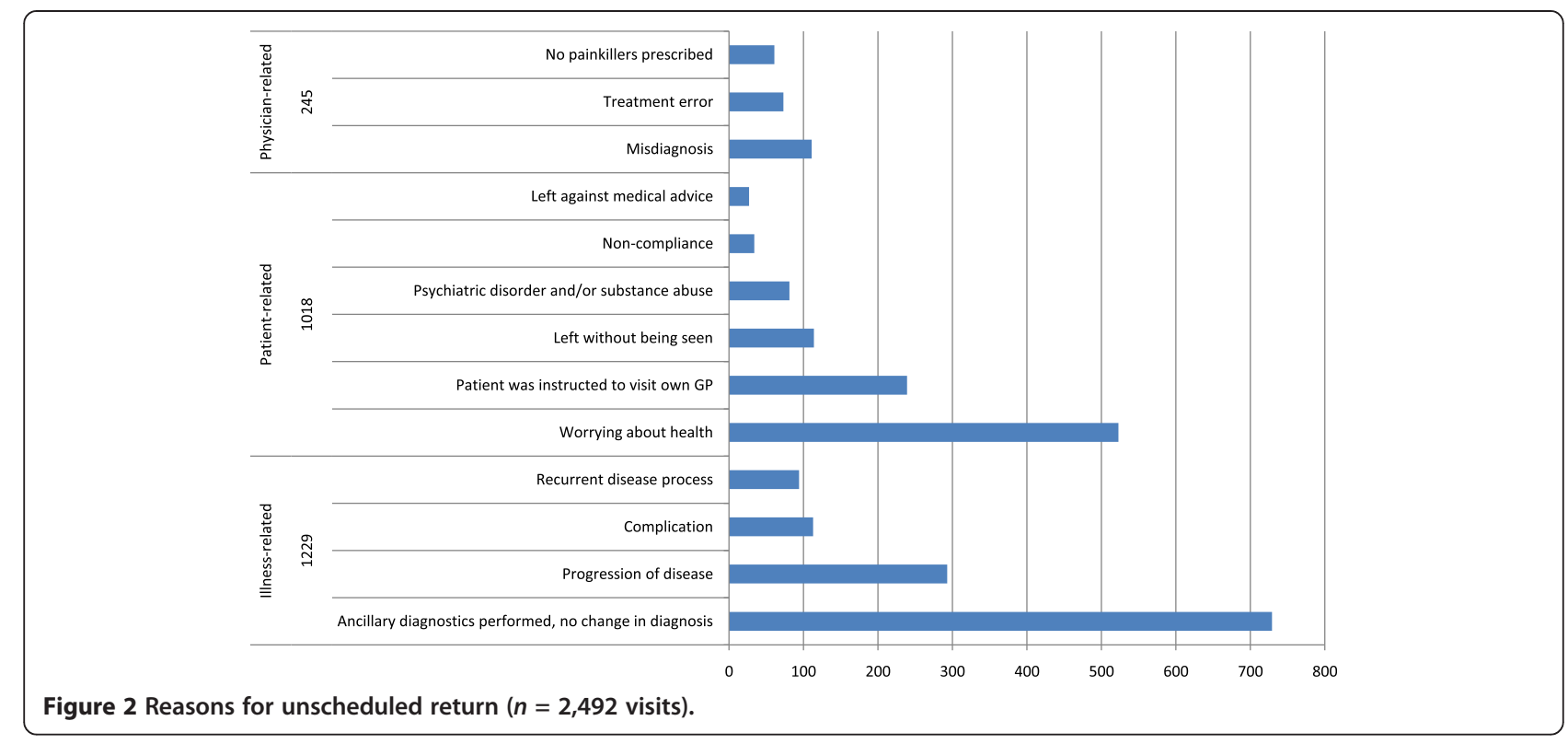

their return. In 73 physician-related return visits (30\%), a 'treatment error' was made during the initial visit, such as patients returning with ongoing complaints because a foreign body in a wound was only removed partially. Sixty-one visits (25\%) were caused by a lack of a prescription of painkillers' at the patients' initial visit.

\section{Post-ED disposition}

No differences in post-ED disposition were found between patients with unscheduled return visits and patients who did not return (Table 3). Sixteen percent of the unscheduled return visits resulted in admission, versus $17 \%$ of the visits of patients who did not return.

\section{Discussion}

Our results showed that unscheduled within-week return accounted for $5 \%(2,492 / 49,391)$ of our ED visits, implying an unscheduled return rate of over 200 visits a month.

Despite the Dutch health care system with universal access to primary care, our within-week unscheduled return rate (5\%) was higher than in another study using a cut-off point of a week, in which $3.8 \%$ unscheduled return [25] was observed. One plausible explanation of our high unscheduled return rate may be that patients not always realize that they have access to a GP $24 \mathrm{~h}$ a day. Furthermore, patients with chronic conditions may present to the ED despite the 24-h access to the GP.

Comparison of return visit rates among studies is complicated by the different time frames used. Some studies use 72 -h return visits [2,7,9-11,14,16,21] while others have used a 30-day delay between the two visits $[26,27]$. Applying the 72 -h time frame in our results, our percentage of unscheduled return visits $(2.7 \%)$ compares well with published 72-h return rates, ranging from $2.2 \%$ to $5.5 \%[2,7,9-11,14,16,21]$. However, our sub-analysis showed that a 72 -h cut-off point would have excluded $47 \%$ of the unscheduled return visits, while risk factors were the same as those associated with unscheduled return visits within 1 week.

Some patients with an unscheduled return visit returned more than once during the week after their initial visit. They may have become 'frequent flyers': patients with high ED utilization, sometimes defined as patients visiting the ED seven or more times per year [28]. We did not follow up on our patients with unscheduled return visits, so we cannot present actual numbers on who became a frequent flyer in the 12 months after the initial visit. Frequent ED utilization, in particular by the homeless or substance abusers, seems less a problem in our ED [29] than outlined in the international literature [30].

When interpreting our medical complaint categorization as proxy measure for diagnosis, our results support the finding in a previous study [18] that a digestive diagnosis is a risk factor for unscheduled return. Return visits related to 'abdominal pain' might be explained by the difficulty of diagnosing abdominal disorders, which has a wide range of possible causes [10]. Emergency physicians should be particularly cautious when a patient present with a high risk for return' diagnosis, such as abdominal pain, and consider a follow-up appointment.

When using the medical complaint 'rashes' as proxy for dermatologic condition, our study contradicts the results in the study of Pham et al. [11] as 'rashes' was no risk factor for unscheduled return in our study. Our physicians often refer patients with rashes to the patients' GP. When these patients suffer persisting 
Table 3 Post-ED disposition

\begin{tabular}{llll}
\hline & $\begin{array}{l}\text { Post-ED disposition after a visit of a } \\
\text { patient who did not return }(\boldsymbol{n}=\mathbf{4 1 , 7 5 0 )}\end{array}$ & $\begin{array}{l}\text { Post-ED disposition after } \\
\text { an unscheduled return visit }(\boldsymbol{n}=\mathbf{2 , 4 9 2})\end{array}$ & $\begin{array}{c}\boldsymbol{P} \text { value } \\
\text { a }\end{array}$ \\
\hline Discharge $[n(\%)]$ & $33,770(80.9)$ & $2,037(81.7)$ & 0.29 \\
Hospital admission, regular ward $[n(\%)]$ & $7,145(17.1)$ & $401(16.1)$ & 0.19 \\
Hospital admission, special care $[n(\%)]$ & $76(0.2)$ & $2(0.1)$ & 0.24 \\
Discharge against medical advice or LWBS $^{\mathrm{C}}[n(\%)]$ & $727(1.7)$ & $52(2.1)$ & 0.20 \\
Morgue $[n(\%)]$ & $32(0.1)$ & 0 & 0.17 \\
\hline
\end{tabular}

${ }^{a} \chi^{2}$ test. ${ }^{b}$ Special care: intensive care unit, coronary care unit or stroke unit. ' $\mathrm{CWBS}$ : patients left the ED without being seen by a physician.

problems, they will probably return to their GP instead of to the ED.

Patients presenting with 'chest pain' or 'feeling unwell' were less likely to return unscheduled. These complaints often indicate cardiac problems. Probably these patients are either admitted at their initial visit or receive an appointment for the outpatient clinic. Parents with a 'sick baby' were also less likely to return. These parents are advised to go to the children's hospital in case of ongoing complaints.

In our study, over $4 \%$ of the patients lacked health insurance. Lacking health insurance was not a risk factor for unscheduled return, contradicting previous findings [11]. Our hospital is a regional centre for treatment of people living illegally in the Netherlands. Appointments at the outpatient clinics are arranged for anyone who needs further medical assessment after an ED visit, regardless of insurance status. Therefore, unscheduled return visits are prevented for insured and uninsured patients alike.

In previous research, conflicting findings regarding the association between triage level and unscheduled return are reported. Two studies concerning a paediatric population found that children with a high triage level were more likely to return unscheduled $[14,16]$, while in a study concerning a mixed population, returning patients had low triage levels [11]. In our study, patients with urgent triage levels (at their initial visit) were more likely to incur an unscheduled return visit. Possibly, patients with low triage levels were advised to return to their GP in case of persisting complaints.

Urgent triage levels may reflect a sicker patient in need for continued medical care. The longer LOS of our returning patients as compared with the LOS of patients who did not return may also indicate a sicker patient. However, our post-ED disposition data showed no sign that returning patients were more seriously ill: returning patients had similar hospital admission rates as the patients who did not return. Future studies should examine outcomes of these patients in more detail.

The percentage of illness-related reasons for unscheduled return in our study (49\%) compares well with the $48 \%$ to $81 \%$ in other studies $[3,7,9]$. Ten percent of our unscheduled return visits were due to physician-related factors, as compared to $3 \%$ to $8 \%$ in other studies $[7,9]$. Patient-related reasons accounted for $41 \%$ of the unscheduled return visits in our study, as compared to $11 \%$ to $53 \%$ in other studies $[6,7,9]$. Most patient-related returns involved patients 'worrying about health', indicating suitability for assessment and reassurance by the GP.

\section{Limitations and strengths}

This study conveys the experience of a single institution and may have limited generalizability because of the social and cultural characteristics of our population and differences in health care delivery in our country. Our findings should be validated in other EDs.

Second, we used routinely collected data. This had the advantage of examining data of large numbers of patients. The disadvantage was that we were not able to account for socio-economic factors that are known to influence the probability of ED return visits, such as marital status, socioeconomic status (SES), alcohol consumption and homelessness $[11,18,31]$. The weak discriminative capacity of our identified predictors for unscheduled return indicates that a future prospective study is needed to include these additional risk factors. However, such a study design should take into account the reliability issues associated with measuring SES and alcohol consumption in ED patients.

The categorization of the reasons of unscheduled return based on retrospective patient documentation was a limitation of our study, which we tried to limit by using explicit criteria for the categories based on previous research $[6,9,23]$.

Another limitation is that not only patients who 'lack health insurance' or 'lack a GP' are registered as such. When it is unclear whether the patient has a health insurance and/or when the patient does not know the name of his/her GP, the patients are also registered as 'lacking health insurance' and/or 'lacking a GP'. Therefore, patients might have been wrongly classified to the 'lack health insurance' or 'lack GP' group, thereby diluting a possible association between health insurance/GPstatus and unscheduled return.

The strengths of this study include its complete data collection. The 11 patient records that were unavailable 
concerned only one patient, so selection bias was negligible. However, patients may have visited other hospital EDs after their visit to the study setting which may have led to some cases not identified.

\section{Conclusions}

Unscheduled within-week return accounted for $5 \%$ of the ED visits. Most associated factors (an urgent triage level, arriving during the night, suffering from a wound or local infection, or a urinary problem) differ from previous studies, except for abdominal complaints, which was found to be a risk factor in many other studies. The reasons for ED return were comparable with studies from other countries: most often illness-related, then patient-related and least often physician-related reasons (e.g. ongoing complaints because a foreign body left behind in a wound or lack of a prescription of painkillers) prompted the patient back to the ED. Short-term follow-up at the outpatient clinic or GP for patients with urgent triage levels and suffering from wounds or local infections, abdominal pain or urinary problem might prevent unscheduled return.

\section{Abbreviations \\ AUC ROC: area under the receiver operating curve; $\mathrm{Cl}$ : confidence interval; ED: emergency department; GP: general practitioner; LOS: length of stay; LWBS: left the emergency department without being seen by a physician; OR: odds ratio; SES: socio-economic status.}

\section{Competing interests}

The authors declare that they have no competing interests.

\section{Authors' contributions}

MCL had full access to all of the data in the study and takes ful responsibility for the integrity of the data and the accuracy of the data analysis. MCL, RL, NL and ERJTD conceived and designed the study. MCL, NL and ERJTD acquired the data. MCL, RL, NL and $C L$ analysed and interpreted the data. MCL and RL drafted the manuscript. $R L, R H, C L$, SJR and JCG critically revised the manuscript for important intellectual content. All authors read and approved the final manuscript.

\section{Author details}

${ }^{1}$ Accident and Emergency Department, Medical Centre Haaglanden, P.O. Box 432, The Hague 2501 CK, The Netherlands. ${ }^{2}$ Division of Clinical Methods and Public Health, Master Evidence Based Practice, Academic Medical Centre, University of Amsterdam, P.O. Box 22660, Amsterdam 1100 DD, The Netherlands. ${ }^{3}$ Clinical Research Unit, Academic Medical Centre, University of Amsterdam, J1b-118, P.O. Box 2260, Amsterdam 1100 DD, The Netherlands. ${ }^{4}$ Institute for Medical Technology Assessment, Erasmus University Rotterdam, P.O. Box 1738, Rotterdam 3000 DR, The Netherlands. ${ }^{5}$ Department of Surgery, Trauma Unit, Academic Medical Centre, University of Amsterdam, P.O. Box 22660, Amsterdam 1100 DD, The Netherlands.

Received: 4 March 2014 Accepted: 23 May 2014 Published online: 05 July 2014

\section{References}

1. Nunez S, Hexdall A, Aguirre-Jaime A: Unscheduled returns to the emergency department: an outcome of medical errors? Qual Saf Health Care 2006, 15:102-108.

2. Foran A, Wuerth-Sarvis B, Milne WK: Bounce-back visits in a rural emergency department. Can J Rural Med 2010, 15:108-112.

3. Hu KW, Lu YH, Lin HJ, Guo HR, Foo NP: Unscheduled return visits with and without admission post emergency department discharge. J Emerg Med 2012, 43:1110-1118.
4. Khan NU, Razzak JA, Saleem AF, Khan UR, Mir MU, Aashiq B: Unplanned return visit to emergency department: a descriptive study from a tertiary care hospital in a low-income country. Eur J Emerg Med 2011, 18:276-278.

5. Pham JC, Trueger NS, Hilton J, Khare RK, Smith JP, Bernstein SL: Interventions to improve patient-centered care during times of emergency department crowding. Acad Emerg Med 2011, 18:1289-1294.

6. Pierce JM, Kellerman AL, Oster C: "Bounces": an analysis of short-term return visits to a public hospital emergency department. Ann Emerg Med 1990, 19:752-757

7. Robinson K, Lam B: Early emergency department representations. Emerg Med Australas 2013, 25:140-146.

8. Sauvin G, Freund $Y$, Saidi K, Riou B, Hausfater P: Unscheduled return visits to the emergency department: consequences for triage. Acad Emerg Med 2013, 20:33-39.

9. Wu CL, Wang FT, Chiang YC, Chiu YF, Lin TG, Fu LF, Tsai TL: Unplanned emergency department revisits within 72 hours to a secondary teaching referral hospital in Taiwan. J Emerg Med 2010, 38:512-517.

10. White D, Kaplan L, Eddy L: Characteristics of patients who return to the emergency department within 72 hours in one community hospital. Adv Emerg Nurs J 2011, 33:344-353.

11. Pham JC, Kirsch TD, Hill PM, DeRuggerio K, Hoffmann B: Seventy-two-hour returns may not be a good indicator of safety in the emergency department: a national study. Acad Emerg Med 2011, 18:390-397.

12. Riggs JE, Davis SM, Hobbs GR, Paulson DJ, Chinnis AS, Heilman PL: Association between early returns and frequent $E D$ visits at a rural academic medical center. Am J Emerg Med 2003, 21:30-31.

13. Safwenberg $U$, Terent $A$, Lind L: Increased long-term mortality in patients with repeated visits to the emergency department. Eur J Emerg Med 2010, 17:274-279.

14. Goldman RD, Ong M, Macpherson A: Unscheduled return visits to the pediatric emergency department-one-year experience. Pediatr Emerg Care 2006, 22:545-549.

15. Gordon JA, An LC, Hayward RA, Williams BC: Initial emergency department diagnosis and return visits: risk versus perception. Ann Emerg Med 1998, 32:569-573

16. Jacobstein CR, Alessandrini EA, Lavelle JM, Shaw KN: Unscheduled revisits to a pediatric emergency department: risk factors for children with fever or infection-related complaints. Pediatr Emerg Care 2005, 21:816-821.

17. LaMantia MA, Platts-Mills TF, Biese K, Khandelwal C, Forbach C, Cairns CB, Busby-Whitehead J, Kizer JS: Predicting hospital admission and returns to the emergency department for elderly patients. Acad Emerg Med 2010, 17:252-259.

18. McCusker J, Cardin S, Bellavance F, Belzile E: Return to the emergency department among elders: patterns and predictors. Acad Emerg Med 2000, 7:249-259.

19. Zimmerman DR, McCarten-Gibbs KA, DeNoble DH, Borger C, Fleming J, Hsieh M, Langer JC, Breckenridge MB: Repeat pediatric visits to a general emergency department. Ann Emerg Med 1996, 28:467-473.

20. Newton AS, Ali S, Johnson DW, Haines C, Rosychuk RJ, Keaschuk RA, Jacobs P, Cappelli M, Klassen TP: Who comes back? Characteristics and predictors of return to emergency department services for pediatric mental health care. Acad Emerg Med 2010, 17:177-186.

21. Kuan WS, Mahadevan M: Emergency unscheduled returns: can we do better? Singapore Med J 2009, 50:1068-1071.

22. Baer RB, Pasternack JS, Zwemer FL Jr: Recently discharged inpatients as a source of emergency department overcrowding. Acad Emerg Med 2001, 8:1091-1094.

23. Keith KD, Bocka JJ, Kobernick MS, Krome RL, Ross MA: Emergency department revisits. Ann Emerg Med 1989, 18:964-968.

24. Hosmer D, Lemeshow S: Applied Logistic Regression. Hoboken, New Jersey: John Wiley \& Sons; 2000.

25. Hu SC: Analysis of patient revisits to the emergency department. Am J Emerg Med 1992, 10:366-370.

26. Geirsson OP, Gunnarsdottir OS, Baldursson J, Hrafnkelsson B, Rafnsson V Risk of repeat visits, hospitalisation and death after uncompleted and completed visits to the emergency department: a prospective observation study. Emerg Med J 2013, 30:662-668.

27. Madsen TE, Bennett A, Groke S, Zink A, McCowan C, Hernandez A, Knapp S, Byreddy D, Mattsson S, Quick N: Emergency department patients with psychiatric complaints return at higher rates than controls. West J Emerg Med 2009, 10:268-272. 
28. Doupe MB, Palatnick W, Day S, Chateau D, Soodeen RA, Burchill C, Derksen S: Frequent users of emergency departments: developing standard definitions and defining prominent risk factors. Ann Emerg Med 2012. 60:24-32.

29. van der Linden $M C$, van den Brand $C L$, van der Linden $N$, Rambach $A H$, Brumsen C: Rate, characteristics, and factors associated with high emergency department utilization. Int J Emerg Med 2014, 7:9.

30. LaCalle $E$, Rabin E: Frequent users of emergency departments: the myths, the data, and the policy implications. Ann Emerg Med 2010, 56:42-48.

31. Moore G, Gerdtz M, Manias E, Hepworth G, Dent A: Socio-demographic and clinical characteristics of re-presentation to an Australian inner-city emergency department: implications for service delivery. BMC Public Health 2007, 7:320.

\section{doi:10.1186/s12245-014-0023-6}

Cite this article as: van der Linden et al: Unscheduled return visits to a

Dutch inner-city emergency department. International Journal of

Emergency Medicine 2014 7:23.

\section{Submit your manuscript to a SpringerOpen ${ }^{\circ}$ journal and benefit from:}

- Convenient online submission

- Rigorous peer review

- Immediate publication on acceptance

- Open access: articles freely available online

- High visibility within the field

- Retaining the copyright to your article 